\title{
Current neurologic treatment and emerging therapies in CDKL5 deficiency disorder
}

Heather E. Olson ${ }^{1 *+} \mathbb{D}$, Carolyn I. Daniels ${ }^{1+}$, Isabel Haviland ${ }^{1+} \mathbb{D}$, Lindsay C. Swanson ${ }^{1}$, Caitlin A. Greene ${ }^{1}$, Anne Marie M. Denny ${ }^{1,2}$, Scott T. Demarest ${ }^{3,4}$, Elia Pestana-Knight ${ }^{5}$, Xiaoming Zhang ${ }^{5}$, Ahsan N. Moosa ${ }^{5}$, Andrea Fidell ${ }^{3,4}$, Judith L. Weisenberg ${ }^{6}$, Bernhard Suter ${ }^{7}$, Cary Fu ${ }^{8}$, Jeffrey L. Neul ${ }^{8}$, Alan K. Percy ${ }^{9}$, Eric D. Marsh ${ }^{10}$, Timothy A. Benke $3,4,11+$ and Annapurna Poduri ${ }^{1+}$

\begin{abstract}
Background: CDKL5 deficiency disorder (CDD) is associated with refractory infantile onset epilepsy, global developmental delay, and variable features that include sleep, behavioral disturbances, and movement disorders. Current treatment is primarily symptom-based and informed by experience in caring for this population.

Methods: We describe medication and non-medication approaches to treatment of epilepsy and additional key neurologic symptoms (sleep disturbances, behavioral issues, movement disorders, and swallowing dysfunction) in a cohort of 177 individuals meeting criteria for CDD, 154 evaluated at 4 CDKL5 Centers of Excellence in the USA and 40 identified through the NIH Natural History Study of Rett and Related Disorders.
\end{abstract}

Results: The four most frequently prescribed anti-seizure medications were broad spectrum, prescribed in over 50\% of individuals. While the goal was not to ascertain efficacy, we obtained data from 86 individuals regarding response to treatment, with 2-week response achieved in 14-48\% and sustained 3-month response in 5-36\%, of those with known response. Additional treatments for seizures included cannabis derivatives, tried in over one-third of individuals, and clinical trial medications. In combination with pharmacological treatment, 50\% of individuals were treated with ketogenic diet for attempted seizure control. Surgical approaches included vagus nerve stimulators, functional hemispherectomy, and corpus callosotomy, but numbers were too limited to assess response. Nearly one-third of individuals received pharmacologic treatment for sleep disturbances, 13\% for behavioral dysregulation and movement disorders, and $43 \%$ had gastrostomy tubes.

\footnotetext{
* Correspondence: Heather.Olson@childrens.harvard.edu

${ }^{+}$Heather E. Olson, Carolyn I. Daniels, and Isabel Haviland are co-first authors.

TTimothy A. Benke and Annapurna Poduri are co-last authors.

'Division of Epilepsy and Clinical Neurophysiology, Department of

Neurology, Boston Children's Hospital, 300 Longwood Avenue, Mailstop

3063, Boston, MA 02115, USA

Full list of author information is available at the end of the article
}

(C) The Author(s). 2021 Open Access This article is licensed under a Creative Commons Attribution 4.0 International License, which permits use, sharing, adaptation, distribution and reproduction in any medium or format, as long as you give appropriate credit to the original author(s) and the source, provide a link to the Creative Commons licence, and indicate if changes were made. The images or other third party material in this article are included in the article's Creative Commons licence, unless indicated otherwise in a credit line to the material. If material is not included in the article's Creative Commons licence and your intended use is not permitted by statutory regulation or exceeds the permitted use, you will need to obtain permission directly from the copyright holder. To view a copy of this licence, visit http://creativecommons.org/licenses/by/4.0/. The Creative Commons Public Domain Dedication waiver (http://creativecommons.org/publicdomain/zero/1.0/) applies to the data made available in this article, unless otherwise stated in a credit line to the data. 
Conclusions: Treatment for neurologic features of CDD is currently symptom-based and empiric rather than CDDspecific, though clinical trials for CDD are emerging. Epilepsy in this population is highly refractory, and no specific anti-seizure medication was associated with improved seizure control. Ketogenic diet is commonly used in patients with CDD. While behavioral interventions are commonly instituted, information on the use of medications for sleep, behavioral management, and movement disorders is sparse and would benefit from further characterization and optimization of treatment approaches. The heterogeneity in treatment approaches highlights the need for systematic review and guidelines for CDD. Additional disease-specific and disease-modifying treatments are in development.

Keywords: CDKL5 deficiency disorder, Developmental encephalopathy, Epileptic encephalopathy, Ketogenic diet, Vagus nerve stimulator, Movement disorders, Clinical trials, Emerging therapies

\section{Background}

CDKL5 deficiency disorder (CDD) is an X-linked disorder that represents one of the more common causes of genetic childhood-onset developmental and epileptic encephalopathy, with an estimated prevalence of one in 40,000 to 60,000 births [1-3]. CDD was previously considered an early onset seizure variant of Rett syndrome $[2,4]$, but has since been distinguished due to the disorder's more severe developmental delays; increased likelihood of epilepsy, sleep abnormalities, and gastrointestinal problems; and lack of early regression following a period of normal development that is typical in Rett [5-10]. In 2019, minimum diagnostic criteria for CDD were proposed to include the presence of a pathogenic or likely pathogenic variant in CDKL5, epilepsy onset within 1 year of age, and motor and cognitive delays [2]. Key clinical features include refractory epilepsy, with onset at less than 3 months in $90 \%$ of individuals (median 5 weeks, IQR 3 to 8 weeks) [1], hypotonia, severe developmental delay/intellectual disability, and cortical visual impairment $[1,2,10]$. Both cognitive impairment and refractory epilepsy in individuals with CDD are particularly severe, and fewer than half of individuals have reported a period of seizure freedom of more than 2 months, with only $12 \%$ experiencing seizure freedom for more than 12 months $[3,10]$.

Patients with CDD typically have several seizure types, with one study reporting an average of 2.8 (SD 1.4) different seizure types at any time [2]. Epileptic spasms (with or without hypsarrhythmia), tonic seizures, and generalized tonic-clonic seizures are most common, and seizures with multiple phases (such as the hypermotortonic-spasms sequence) are also common [1,2]. Epilepsy tends to evolve to generalized or mixed focal and generalized patterns [2].

Data on response to available treatment for epilepsy in CDD remain limited, though case series suggest that symptoms are highly refractory to treatment $[1-3,6$, 11-15]. One retrospective review of anti-seizure medication (ASM) response in 39 individuals with CDD demonstrated a responder rate $(>50 \%$ reduction in seizure frequency) to at least one ASM or to ketogenic diet (KD) of $69 \%$ at 3 months, falling to $24 \%$ at 12 months [11]. Additionally, $31 \%$ of individuals experienced seizure aggravation with at least one ASM [11]. Data from the International CDKL5 Disorder Database (ICDD) further suggest that the most commonly prescribed ASMs are broad-spectrum medications including clobazam, topiramate, and levetiracetam, and that almost one-third of individuals are treated with steroids at some point [3]. Limited retrospective data suggest that $\mathrm{KD}$ and vagus nerve stimulator (VNS) treatment may have some benefit [12, 13].

Although seizures are an early and prominent clinical feature of CDD, other neurological symptoms are equally prominent, including sleep dysfunction, behavioral dysregulation, movement disorders, and swallowing dysfunction. The majority of individuals with CDD experience clinically significant sleep problems $[7,16-$ 18], with concerns including diurnal problems, bruxism, night screaming, night laughing, and night waking [7]. Comorbidities of CDD such as severe hypotonia and autonomic dysfunction may contribute to obstructive airway symptoms and central sleep apnea, respectively [16]. Reports on behavioral dysregulation associated with $\mathrm{CDD}$ are limited; however, there are several case reports of individuals with autistic features and perseverative, self-centered behavior [5, 15, 19-24]. Movement disorders described in individuals with $\mathrm{CDD}$ include dyskinesias, chorea, ballismus, myoclonus, and hand stereotypies $[6,16,24]$. Dysphagia is common in CDD and data from the International CDKL5 Disorder Database suggested that $20.7 \%$ of individuals were fed exclusively by gastrostomy or nasogastric tube [7]. Like epilepsy, these additional neurological symptoms negatively impact individuals' quality of life and may be treatable by medication and non-medication approaches, thus are important to understand how to manage $[18,25]$.

We aim to describe current treatment approaches and emerging therapies for epilepsy and additional treatable neurological symptoms (sleep dysfunction, behavioral 
dysregulation, movement disorders, and swallowing dysfunction) in individuals with CDKL5 deficiency disorder at experienced centers. This complements ongoing efforts towards defining treatment guidelines for CDD.

\section{Methods \\ CDD cohort}

In collaboration with the International Foundation for CDKL5 Research, dedicated Centers of Excellence (COEs) were established for expert care of children with CDD and parallel clinical research [1]. Our cohorts consisted of individuals with CDD seen in COEs at Boston Children's Hospital (BCH, $n=56)$, Cleveland Clinic Foundation (CCF, $n=30$ ), University of Colorado/Children's Hospital Colorado (CHCO, $n=51$ ), and Baylor College of Medicine (BCM, $n=17$ ). BCM provided data exclusively on movement disorders in CDD patients. In partnership with the NIH-funded Natural History Study of Rett and Related Disorders (NHS, U54 HD061222; NCT02738281), data related to anti-seizure treatments, as well as medications for sleep dysfunction and behavioral dysregulation, were gathered from an additional cohort of 40 individuals with CDD that represents individuals enrolled across 10 clinical sites, and excluded individuals already captured in $\mathrm{BCH}, \mathrm{CCF}$, and $\mathrm{CHCO}$ $\mathrm{COE}$ cohorts. Inclusion criteria included meeting consensus criteria for CDD: a pathogenic or likely pathogenic variant in CDKL5 gene, motor and cognitive developmental delays, and epilepsy with onset in the first year of life [2]. Each center has an Institutional Review Board (IRB)-approved protocol for prospective and retrospective collection of clinical data, including data from medical records, on individuals with CDD. Clinical and genetic data are gathered using standardized clinical research forms across the Centers of Excellence, and maintained in separate REDCap databases. IRB approval exists for all sites in the NHS.

\section{Evaluation of neurologic management}

Data were collected both retrospectively and prospectively through the dedicated COEs as part of a clinicbased research study. Physicians in the Centers of Excellence included neurologists and other pediatric specialists, for example gastroenterologists. Medical records and standardized clinical research forms were reviewed to evaluate medication and non-medication treatment approaches for epilepsy, sleep dysfunction, behavioral dysregulation, and movement disorders. For epilepsy, we tabulated ASMs used including response and tolerance, as well as use of ketogenic diet, vagus nerve stimulator, and epilepsy surgery. For ASMs, a positive response was defined as a $50 \%$ or greater reduction in at least one seizure type sustained for two time periods: 2 weeks and 3 months, as best estimated based on retrospective review of medical records including clinic, hospital, and phone notes. NHS data were obtained as part of initial and yearly research visits. Data on sleep and behavioral medications were collected at $\mathrm{BCH}, \mathrm{CCF}$, and through NHS. Data on movement medications were collected at $\mathrm{BCH}, \mathrm{CCF}$, and BCM. Data on gastrostomy tubes were collected from $\mathrm{BCH}$ and $\mathrm{CHCO}$ COEs. Data on response to treatment were not part of clinical research forms or NHS data collection and were only collected at $\mathrm{BCH}$ and CCF based on review of medical records. Though EEG data were available for some patients, EEG data were not used routinely to quantify response to treatment. Cannabis derivatives, including Epidiolex and non-FDA approved derivatives, are described separately because cannabis derivatives were included as a general category, without specifying whether they referred to Epidiolex or not, in some of the dataset. Seizure data were gathered for COE patients based on medical record review and from standardized research forms. All seizure types occurring in CDD, including infantile spasms, were included. Seizure classification was conducted using International League Against Epilepsy (ILAE) guidelines [26].

\section{Statistical analysis}

Descriptive statistical methods were used, using Microsoft Excel (Version 14.7.7) and IBM SPSS Statistics (Version 27).

\section{Results}

\section{Demographic characteristics}

Of 177 individuals with CDD seen at three CDKL5 COEs and 10 NHS sites across the USA, $82 \%$ of individuals were female $(n=145)$ and $18 \%$ were male $(n=32)$. CDKL5 variants included truncating variants in 63 , missense variants in the kinase domain in 44, partial or fullgene deletions in 20 , splice variants in 6 , and unknown protein impacts in 4 . All variants were de novo when inheritance information was available. Median age at time of data collection was 8.1 years (range 8 months to 39 years). Data on race and ethnicity were available for 126 individuals, with $82 \%$ of individuals reported as white, 6\% reported as Asian, and 3\% reported as Black or African American. In addition, 4\% reported membership in more than one racial category, $0.7 \%$ reported racial category as "other," $0.7 \%$ did not provide racial category, and for $1 \%$, racial category was unknown. In addition to racial category, $12 \%$ of individuals reported Hispanic, Latino/a or Spanish origin.

\section{Seizure types}

Seizure types were known for 136 patients from three COEs. The most common seizure types at any time 
point included spasms $(n=90,66 \%)$, generalized tonic $(n=82,60 \%)$, focal seizures $(n=69,51 \%)$, generalized myoclonic $(n=60,44 \%)$, and generalized tonic-clonic ( $n$ $=57,42 \%)$. Seizures with multiple phases were seen in $41 \%$ of patients.

\section{Anti-seizure medications}

Data on ASM treatment were available from 168 individuals from the three COEs and through NHS. The median number of anti-seizure medications prescribed per individual (lifetime use) was 6 (range 0 to 18). In total, 33 different ASMs were prescribed in this group of individuals. The most frequently prescribed medications (prescribed in more than 50\% of individuals) were levetiracetam $(n=136)$, topiramate $(n=107)$, clobazam $(n=$ $100)$, and phenobarbital $(n=89)$. For 86 individuals with treatment response data for the most frequently prescribed medications, 2-week sustained response, defined as $50 \%$ or greater reduction in at least one seizure type during this time frame, was reported for 14 to $48 \%$ of individuals (of those with known response) (Table 1). A 3month response, however, was reported in only 5-36\%. Worsening seizures attributable to ASMs were reported in 39 individuals $(39 / 88,44 \%)$. Details on ASM response for all medications prescribed can be found in Table 1.

Sixty-one individuals $(n=61$ of $168,36 \%)$, out of the total number of individuals with ASM data, were treated with cannabis derivatives, including FDA-approved cannabidiol (Epidiolex), and non-FDA-approved cannabis derivatives. This was predominantly in combination with other epilepsy treatments. Of 86 individuals for whom Epidiolex was differentiated from non-FDA-approved cannabis derivatives, 19 reported using Epidiolex (22\%) and 18 reported using non-FDA-approved cannabis derivatives. Two-week response, for those with known response, was reported for Epidiolex in $29 \%$ of individuals and sustained for 3 months in $21 \%$, compared to $50 \%$ of those with known response for both time periods for non-FDA-approved cannabis derivatives (Table 2).

Medications and treatments reported to be most helpful for seizure control, based on a specific question on our standardized research forms as well as on caregiver and clinician's impression, were listed for 41 individuals and included the following (percentages are based on number of patients who were prescribed each medication): clobazam ( $n=10$ of $28,36 \%)$, ketogenic diet $(n=$ 6 of $28,21 \%$ ), topiramate $(n=5$ of $29,17 \%$ ), prednisolone/prednisone ( $n=5$ of $15,33 \%)$, АCTH ( $n=5$ of 17 , $29 \%)$, valproic acid $(n=4$ of $22,18 \%)$, lamotrigine $(n=4$ of $12,33 \%$ ), vigabatrin ( $n=3$ of $22,14 \%)$, rufinamide ( $n$ $=3$ of $17,18 \%)$, Epidiolex ( $n=2$ of 7, 29\%), clonazepam ( $n=2$ of $15,13 \%)$, non-FDA-approved cannabis derivatives $(n=2$ of $4,50 \%)$, zonisamide $(n=1$ of $12,8 \%)$, brivaracetam $(n=1$ of $1,100 \%)$, lacosamide $(n=1$ of 7 ,
$14 \%)$, felbamate ( $n=1$ of $6,17 \%)$, and levetiracetam $(n=$ 1 of $37,3 \%)$.

\section{Ketogenic diet}

Eighty-nine of 177 individuals (50\%) were placed on the ketogenic diet at some point in their treatment course. Details on the use of KD were available for 54 patients. Median age of diet initiation was 1.92 years (range 6 weeks to 10 years), with 13 (24\%) starting before 12 months. Thirty-two individuals used the diet for a finite period of time (median of 11 months, range 1 month to 8 years), and 15 individuals remained on the diet at last clinic visit. Duration of use was unknown for the remaining individuals $(n=7)$. Seizure frequency at the time of diet initiation was daily in 42 of 54 individuals (78\%, ranging from 1 to 30 seizures per day), weekly for one individual, and unknown for the remaining 11 individuals. Six of the 54 total individuals who tried KD (11\%) reported increase in seizures on the diet, 2 of whom had increased seizures at higher ratios but improvement in seizures at lower ratios. Most common side effects and complications reported, consistent with expectations for KD treatment, were gastrointestinal issues including reflux, constipation, vomiting, and gastrointestinal distress $(n=7)$, acidosis $(n=6)$, feeding difficulties $(n=5)$, hypoglycemia $(n=4)$, lethargy $(n=$ $3)$, and aspiration pneumonia $(n=2)$.

Clinically significant seizure response to the diet was known for 44 individuals. Twenty-two of 44 individuals (50\%) were responders (time point of evaluation unspecified). In three individuals (considered as nonresponders), benefit was more modest, with a decrease in seizure frequency below $50 \%$. Twenty-two individuals (50\%) did not respond to the diet. Although the mean age of those who responded to KD (1.75 years) was lower than that of non-responders (3.0 years), this difference was not statistically significant with Mann-Whitney $U$ test $(p=0.105)$. Eight of 10 individuals $(80 \%)$ who started the diet at $<12$ months had a clinically significant reduction in seizures, and two individuals $(20 \%)$ did not respond to KD treatment. Thirteen of 31 individuals who started the diet at or after age 1 year (of those with known response) responded to the diet (42\%). A Fisher's exact test comparing response between individuals who started KD at $<12$ months vs $\geq 12$ months was statistically significant $(p=0.067)$. Seven of 22 previously noted responders reported subjective cognitive improvements based on caretaker reports associated with use of the diet, including improved social interaction and mood, increased alertness, and improved developmental progress. Cognitive benefits were reported in four nonresponders. Nineteen individuals did not have cognitive improvements with ketogenic diet, and information was not available for 5 individuals. Summary of response to 
Table 1 Summary of response of 86 individuals with CDD to anti-seizure medications

\begin{tabular}{|c|c|c|c|c|c|c|}
\hline Medication & $\begin{array}{l}\# \\
\text { individuals }\end{array}$ & $\begin{array}{l}\# \\
\text { individuals } \\
\text { with known } \\
\text { response }\end{array}$ & $\begin{array}{l}\text { 2-week response ( } n,(\% \text { of } \\
\text { those prescribed the } \\
\text { medication with known } \\
\text { response)) }\end{array}$ & $\begin{array}{l}\text { 3-month response ( } n \text {, }(\% \\
\text { of those prescribed the } \\
\text { medication with known } \\
\text { response)) }\end{array}$ & $\begin{array}{l}\text { Worsening seizures ( } n \text {, }(\% \\
\text { of those prescribed the } \\
\text { medication with known } \\
\text { response)) }\end{array}$ & $\begin{array}{l}\text { No change ( } n,(\% \text { of } \\
\text { those prescribed the } \\
\text { medication with known } \\
\text { response)) }\end{array}$ \\
\hline Levetiracetam & 75 & $56(75 \%)$ & $8(14 \%)$ & $3(5 \%)$ & $5(9 \%)$ & $43(77 \%)$ \\
\hline Topiramate & 57 & $38(67 \%)$ & $10(26 \%)$ & $5(13 \%)$ & $2(5 \%)$ & $26(68 \%)$ \\
\hline Phenobarbital & 53 & $35(66 \%)$ & $13(37 \%)$ & $3(9 \%)$ & $1(3 \%)$ & $21(60 \%)$ \\
\hline Clobazam & 52 & $25(48 \%)$ & $12(48 \%)$ & $9(36 \%)$ & $4(16 \%)$ & $10(40 \%)$ \\
\hline Vigabatrin & 41 & $27(66 \%)$ & 15 (56\%) & $9(33 \%)$ & $2(7 \%)$ & $9(33 \%)$ \\
\hline Valproic acid & 40 & $25(63 \%)$ & $9(36 \%)$ & $7(28 \%)$ & 0 & $16(64 \%)$ \\
\hline Oxcarbazepine & 31 & $20(65 \%)$ & $5(25 \%)$ & $2(10 \%)$ & $3(15 \%)$ & $12(60 \%$ \\
\hline ACTH & 30 & $19(19 \%)$ & $8(42 \%)$ & 0 & $1(5 \%)$ & $10(53 \%$ \\
\hline Clonazepam & 30 & $11(37 \%)$ & 0 & 0 & $2(18 \%)$ & $9(82 \%)$ \\
\hline $\begin{array}{l}\text { Prednisolone/ } \\
\text { prednisone }\end{array}$ & 28 & $21(75 \%)$ & 7 (33\%) & 0 & $1(5 \%)$ & $13(62 \%)$ \\
\hline Rufinamide & 28 & $15(54 \%)$ & $7(47 \%)$ & $4(27 \%)$ & $3(20 \%)$ & $6(40 \%)$ \\
\hline Lamotrigine & 26 & $15(58 \%)$ & $6(40 \%)$ & $2(13 \%)$ & $1(7 \%)$ & $8(53 \%)$ \\
\hline Zonisamide & 22 & $13(59 \%)$ & 0 & 0 & $1(8 \%)$ & $12(92 \%)$ \\
\hline $\begin{array}{l}\text { Cannabidiol } \\
\text { (Epidiolex) }\end{array}$ & 19 & $14(74 \%)$ & $4(29 \%)$ & $3(21 \%)$ & $4(29 \%)$ & $6(43 \%)$ \\
\hline Lacosamide & 12 & $9(75 \%)$ & 0 & 0 & $2(22 \%)$ & $7(78 \%)$ \\
\hline Felbamate & 11 & $5(45 \%)$ & $1(20 \%)$ & $1(20 \%)$ & 0 & $4(80 \%)$ \\
\hline Carbamazepine & 10 & $6(60 \%)$ & 0 & 0 & 0 & $6(100 \%)$ \\
\hline Phenytoin & 10 & $8(80 \%)$ & $1(13 \%)$ & $1(13 \%)$ & $2(25 \%)$ & $5(63 \%)$ \\
\hline Clorazepate & 7 & $4(57 \%)$ & 0 & 0 & $1(25 \%)$ & $3(75 \%)$ \\
\hline Gabapentin & 5 & $4(80 \%)$ & 0 & 0 & 0 & $4(100 \%)$ \\
\hline Perampanel & 5 & $4(80 \%)$ & 0 & 0 & 0 & $4(100 \%)$ \\
\hline Ethosuximide & 4 & $1(25 \%)$ & 0 & 0 & 0 & $1(100 \%)$ \\
\hline Diazepam & 3 & $1(33 \%)$ & 0 & 0 & 0 & $1(100 \%)$ \\
\hline Lorazepam & 3 & $2(67 \%)$ & $1(50 \%)$ & $1(50 \%)$ & $2(100 \%)$ & 0 \\
\hline Nitrazepam & 3 & $1(33 \%)$ & 0 & 0 & 0 & $1(100 \%)$ \\
\hline Pregabalin & 3 & $1(33 \%)$ & 0 & 0 & 0 & $1(100 \%)$ \\
\hline Methsuximide & 2 & $1(50 \%)$ & 0 & 0 & 0 & $1(100 \%)$ \\
\hline Midazolam & 2 & $2(100 \%)$ & 0 & 0 & 0 & $2(100 \%)$ \\
\hline Acetazolamide & 1 & 0 & 0 & 0 & 0 & 0 \\
\hline Brivaracetam & 1 & $1(100 \%)$ & $1(100 \%)$ & $1(100 \%)$ & 0 & 0 \\
\hline Fosphenytoin & 1 & $1(100 \%)$ & 0 & 0 & 0 & $1(100 \%)$ \\
\hline Stiripentol & 1 & 0 & 0 & 0 & 0 & 0 \\
\hline Tiagabine & 1 & $1(100 \%)$ & 0 & 0 & 0 & $1(100 \%)$ \\
\hline
\end{tabular}

Table 2 Summary of response to cannabis derivatives for individuals with CDD from two COEs

\begin{tabular}{|c|c|c|c|c|c|c|}
\hline Treatment & $\begin{array}{l}\# \\
\text { individuals }\end{array}$ & $\begin{array}{l}\text { \# individuals } \\
\text { with known } \\
\text { response }\end{array}$ & $\begin{array}{l}\text { 2-week response ( } n, \\
\text { (\% of those taking } \\
\text { with known response)) }\end{array}$ & $\begin{array}{l}\text { 3-month response ( } n \text {, } \\
\text { (\% of those taking with } \\
\text { known response)) }\end{array}$ & $\begin{array}{l}\text { Worsening seizures ( } n \text {, } \\
\text { (\% of those taking with } \\
\text { known response)) }\end{array}$ & $\begin{array}{l}\text { No change ( } n,(\% \text { of } \\
\text { those taking with } \\
\text { known response)) }\end{array}$ \\
\hline $\begin{array}{l}\text { Cannabidiol } \\
\text { (Epidiolex) }\end{array}$ & 19 & 14 (74\%) & $4(29 \%)$ & $3(21 \%)$ & $4(29 \%)$ & $6(43 \%)$ \\
\hline $\begin{array}{l}\text { Non-FDA- } \\
\text { approved } \\
\text { cannabis } \\
\text { derivative }\end{array}$ & 18 & $4(19 \%)$ & $2(50 \%)$ & $2(50 \%)$ & $1(25 \%)$ & $2(50 \%)$ \\
\hline
\end{tabular}


$\mathrm{KD}$, of those with known response, can be found in Table 3. Additional details are included in Supplemental Table 1 (see Supplemental Tables).

\section{VNS and epilepsy surgery}

Thirty-six of 177 individuals (20\%) reported treatment with a vagus nerve stimulator. Median age at VNS placement was 5 years (range 1 year 9 months to 13 years) for 16 individuals with detailed information. Seizure frequency at VNS placement was daily for 12 individuals, weekly for one individual, and unknown for three individuals. Seven individuals $(7 / 16,43 \%)$ reported a decrease in seizure frequency post-implantation at any time point, three individuals reported a decrease in seizure intensity $(3 / 16,18 \%)$, and two individuals reported a decrease in seizure duration $(2 / 16,12 \%)$. There was not enough information in medical records to assess percentage of seizure decrease. Reported side effects included swallowing difficulties in one individual and initial increase in frequency or severity of seizures in two individuals which subsequently improved while continuing with VNS treatment. Additional details on response to VNS treatment can be found in Table 4.

Of 137 individuals, 6 underwent other surgical treatments for epilepsy. One individual had a right functional hemispherectomy at 2 years of age, and seizures persisted post-surgery. Five individuals reported undergoing corpus callosotomy for seizure control, and data on response were available for three of them. One individual reported a significant reduction in seizures, with recurrence after an unspecified period of time. Another individual reported reduction in duration of one seizure type (tonic seizures), and a repeat corpus callosotomy is being considered. Another individual had complete resolution of atonic seizures for approximately 1 year, followed by recurrence at a lower frequency.

\section{Other neurologic symptoms}

Sleep disturbances were reported at any time point in 61 of 86 individuals (71\%). Sleep medications were used in 40 of 126 individuals (32\%), with a range of $1-5$ sleep medications used per person (median $=1$ ). The most commonly prescribed sleep medication was melatonin $(n=30)$, with 10 individuals reporting an improvement in sleep with this medication (30\%). Sixteen of 127 individuals $(13 \%)$ received medications for behavioral management including selective serotonin or serotonin and norepinephrine reuptake inhibitors, atypical antipsychotics, alpha-2 adrenergic receptor agonists, benzodiazepines, and stimulants, the most common indication being irritability $(n=9)$. Additional details on response to prescribed sleep and behavioral medications can be found in Supplemental Table 2 (see Supplemental Tables). Thirty-five of 154 individuals from four COEs (23\%) were described to have movement disorders, the most common being choreoathetosis $(n=16)$, dystonia $(n=7)$, and dyskinesia $(n=4)$. Of 24 individuals with information on pharmacological treatment, three individuals received medications for choreoathetosis (clonidine, tetrabenazine, and risperidone) (13\%). Additionally, at least 40 patients (43.5\% of 92 with available data) had a gastrostomy tube for feeding difficulties including dysphagia. Of 24 patients with data on modified barium swallow studies, dysphagia with risk of aspiration was noted in $14(58.3 \%)$.

\section{Discussion}

In this assessment of current treatment approaches for neurologic aspects of CDD at academic medical centers throughout the USA, we demonstrate that epilepsy is highly refractory, that the most common ASMs prescribed are broad spectrum as appropriate for generalized or mixed-type epilepsy with both focal and generalized seizure types, and that response rate to $\mathrm{KD}$ is likely better than to medication but still variable. Data on VNS and other surgical approaches for epilepsy are limited to our report of exposures, as are data on treatment of other neurologic symptoms, including sleep, behavioral, and movement disorders. Disease-specific clinical trials are underway, and emerging therapies are reviewed below.

The individuals described with CDD were treated for multiple generalized and focal seizure types including tonic, tonic-clonic, myoclonic, and spasms, as well as seizures with multiple phases. A separate study evaluating response of epileptic spasms to first-line treatments in CDD is underway [27]. Response rates to ASMs in our cohort were quite low, ranging from 5 to $36 \%$ at 3 months for the most prescribed medications. It is important to note that patients received multiple ASMs simultaneously, as well as other treatments including cannabis derivatives, trial drugs, $\mathrm{KD}$, and epilepsy surgery, which makes it difficult to draw conclusions about the efficacy of any individual treatment. Clinician and caregiver impression of the most helpful epilepsy treatments included clobazam, topiramate, steroids, valproic

Table 3 Summary of response of 44 individuals with known response to ketogenic diet

\begin{tabular}{llll}
\hline & Age at start of diet (years, median/mean) & Cognitive improvements reported & Side effects reported \\
\hline Responders, $\mathbf{5 0 \%}(\boldsymbol{n}=\mathbf{2 2})$ & $1.17 / 1.75$ & $32 \%(n=7)$ & $64 \%(n=14)$ \\
Non-responders, $\mathbf{5 0 \% (} \boldsymbol{n}=\mathbf{2 2})$ & $1.92 / 3.00$ & $18 \%(n=4)$ & $27 \%(n=6)$ \\
\hline
\end{tabular}


Table 4 Response of 16 individuals with CDD to vagus nerve stimulator

\begin{tabular}{|c|c|c|c|c|}
\hline $\begin{array}{l}\text { Subject } \\
\text { ID }\end{array}$ & $\begin{array}{l}\text { Age at } \\
\text { placement }\end{array}$ & $\begin{array}{l}\text { Seizure frequency at } \\
\text { start of VNS }\end{array}$ & Seizure response & Side effects \\
\hline A11 & Unknown & Daily & No change in seizures & None reported \\
\hline A20 & $\begin{array}{l}9 \text { years } 4 \\
\text { months }\end{array}$ & 2-3/day & $\begin{array}{l}\text { Decreased frequency and severity, decreased } \\
\text { duration with magnet }\end{array}$ & $\begin{array}{l}\text { Initial increase in frequency of seizures prior to } \\
\text { adjustment of settings }\end{array}$ \\
\hline A21 & $\begin{array}{l}6 \text { years } 3 \\
\text { months }\end{array}$ & 5-6/day & Decreased severity & None reported \\
\hline A24 & $\begin{array}{l}1 \text { year } 9 \\
\text { months }\end{array}$ & Daily & Decreased frequency and severity & Swallowing difficulties \\
\hline A25 & $\begin{array}{l}4 \text { years } 3 \\
\text { months }\end{array}$ & Daily & Minimal effect & None reported \\
\hline A26 & 4 years & Unknown & Decreased frequency & None reported \\
\hline A28 & $\begin{array}{l}3 \text { years } 2 \\
\text { months }\end{array}$ & Daily & Decreased frequency & Initial increase in severity of seizures \\
\hline A31 & $\begin{array}{l}2 \text { years } 8 \\
\text { months }\end{array}$ & 8-10 clusters/day & Decreased frequency, response to magnet & None reported \\
\hline A35 & 10 years & Weekly & Decreased duration & None reported \\
\hline A79 & 13 years & Unknown & Decreased duration & None reported \\
\hline B7 & 7.5 years & Daily & No change in seizures & None reported \\
\hline B8 & 5 years & Daily & No change in seizures & None reported \\
\hline B11 & Unknown & Daily & No change in seizures & None reported \\
\hline B14 & Unknown & Daily & Unknown & Unknown \\
\hline B15 & $\begin{array}{l}2 \text { years } 3 \\
\text { months }\end{array}$ & Daily & Slight reduction in seizures & None reported \\
\hline B22 & 7 years & 10-14/day & Reduced seizures to 5-6/day & None reported \\
\hline
\end{tabular}

acid, and lamotrigine. Though we cannot make firm conclusions about efficacy, this is consistent with one additional report in the literature, also based on retrospective review of caretaker and clinician impression, stating that medications with the highest rates of seizure reduction at 3 months include vigabatrin, clobazam, valproic acid, steroids, lamotrigine, felbamate, and zonisamide [11]. The range of response rates to each ASM in this report was broad, with a maximum of $33 \%$ [11]. Despite a low response rate at 3 months, these medications continue to be the most frequently prescribed. While one publication suggested that carbamazepine may exacerbate seizures in $\mathrm{CDD}$, a more recent retrospective study based on a cohort of 21 individuals with CDD reported that sodium channel blockers (SCBs) led to a greater than $50 \%$ seizure reduction for more than 6 months in $31.6 \%$ of participants, and to seizure freedom for more than 5 years in $15.8 \%$, proposing SCBs as a potentially beneficial therapy in well-selected individuals with CDD-related epilepsy [11, 28]. SCBs were used in our cohort, but we did not control for evaluation of individual treatments as was done in Aledo-Serrano's study, so we cannot draw conclusions on the efficacy of particular ASMs by pharmacologic category. Another recent study based on a group of 14 individuals with CDD found that 5 participants responded to a combination of vigabatrin and zonisamide for epileptic spasms [29]. However, our methodology did not allow us to evaluate specific combinations of ASMs and their effects on seizure control. Forty-four percent of the individuals in our study reported worsening seizures associated with ASM treatment, similar to $31 \%$ with seizure aggravation in a prior study, but this exacerbation may be due to the evolution of the disease rather than to medications [11]. None of the patients in our cohort had worsening with carbamazepine, and we did not observe a higher rate of seizure exacerbation with use of SCBs compared to other ASMs, in contrast to the one previous study showing seizure exacerbation with carbamazepine [11].

Our response rate to cannabis derivatives, $21-50 \%$ at 3 months, is in line with what is reported in the only study in the literature that reports the effect of Epidiolex on seizures in individuals with CDD [30], where $41 \%$ were reported as responders at 3 months. Results of this prospective open-label interventional study showed that individuals with CDD had a reduction in motor seizures from median 66.4 per 28 days to 35.8 at 12 weeks, with stable frequency at 48 weeks [30]. The validity of our results is limited due to missing data for those who used non-FDA approved products.

Ketogenic diet is a common treatment for refractory epilepsy [31]. Compared to the prior report on use of 
KD in CDD reporting a median age of initiation of 4.8 years, individuals in our cohort had a median age of initiation of 1.92 years [12]. Rate of improvement of seizures and cognition was similar compared to this prior study, but our study suggests a trend toward a higher percentage of individuals with response in those who initiated the diet before 1 year of age $(80 \%)$ compared to those initiating diet after 1 year of age (42\%) [12]. The difference did not reach statistical significance and would require further research to determine if efficacy may be higher with initiation in infancy.

Surgical approaches for refractory epilepsy in this series included VNS, functional hemispherectomy, and corpus callosotomy. In our cohort, $43 \%$ of individuals reported a decrease in seizure frequency and $18 \%$ reported a decrease in seizure intensity post-VNS implantation, compared to $68 \%$ and $60 \%$, respectively, in a prior study [13]. Additionally, only $12 \%$ of our cohort reported a decrease in seizure duration, versus $72 \%$ of individuals from ICDD [13]. The lower rate of reported response in our study may be due to the comparatively small number of individuals who reported VNS use $(n=16)$, which may limit the representativeness of our sample. Additionally, the COEs represent quaternary care centers and may be biased towards a more severely affected group of individuals. Further study is required to assess corpus callosotomy and other surgical approaches to epilepsy treatment in CDD.

In addition to treatment for seizure control, nearly onethird of individuals received treatment for sleep disturbances, and 13\% received treatment for behavioral dysregulation and movement disorders. Although the prevalence and characteristics of sleep, behavioral, and movement disorders in CDKL5 have been described in the literature $[2,7,16,17]$, data on treatment are limited. Further study is required in each of these areas to assess efficacy of treatments based on specific sub-types of symptoms.

At the 2019 Patient-Focused Drug Development Meeting for CDD, caregivers identified the top 3 most burdensome symptoms for CDD patients as global developmental delay (79\%), epilepsy (63\%), and gastrointestinal and feeding problems (48\%) [32]. Behavioral disturbances were rated as most burdensome by $17 \%$ of caregivers, and sleep problems by $6 \%$, while movement disorders were not selected by any respondents [32]. Additionally, a recent study reported that functional impairment, including lack of ability to sit, use hands, and communicate, was reported to have the greatest adverse impact on quality of life for individuals with CDD [25]. We focused on epilepsy and other neurologic aspects of CDD that are currently treatable in a clinical setting, but further studies characterizing therapy and educational approaches to improving functional impairment and global developmental delay in CDD would be beneficial.

\section{Review of emerging therapies}

Over the last several years, CDD clinicians, researchers and pharmaceutical company partners have collaborated to bring a number of investigational drugs to clinical trials as well as explore emerging precision therapies for CDD. As of December 2020, there have been five clinical trials for the CDD population with seizure management as the primary outcome measure.

The neurosteroid ganaxolone (an analog of allopregnanolone), which is an allosteric modulator of GABA-A receptors, recently completed a phase III clinical trial (NCT03572933) that included a 17-week double blind phase [33, 34]. Results included a significant reduction in major motor seizure frequency in comparison with placebo (32.2\% vs. $4.0 \%)$ [35], and an expanded access program is being developed for ganaxolone in CDD [36].

A phase II open-label study with soticlestat (OV935/ TAK-935) was recently completed for individuals with CDD (NCT03694275) [37]. Soticlestat is a selective cholesterol 24-hydroxylase $(\mathrm{CH} 24 \mathrm{H})$ inhibitor that converts brain cholesterol to 24S-hydroxycholesterol (24HC), which is a positive allosteric modulator of the NMDA receptor [37, 38]. The results from the phase II study show that treated individuals with $\operatorname{CDD}(n=11)$ experienced a $24 \%$ median reduction in major motor seizures during the 12-week maintenance period [37]. Five individuals with $\mathrm{CDD}$ who continued into the open label extension portion of the study achieved a $50 \%$ median motor seizure frequency reduction [37]. The Clinical Global Impression of Change as a secondary end point also demonstrated improvements [37].

Two investigator-initiated studies for therapeutics in CDD were an open-label fenfluramine trial (NCT03861871), and a phase II randomized, placebocontrolled crossover study of ataluren for the treatment of individuals with CDD with nonsense variants in CDKL5 (NCT02758626). Ataluren, a nonaminoglycoside drug, targets pathogenic nonsense variants in other genetic diseases [39]. Results of recent in vitro studies of aminoglycoside drugs demonstrate that nonsense CDKL5 variants are efficiently suppressed, raising the question of utility of ataluren for CDD [39]. Fenfluramine acts on multiple receptors and is involved in the modulation of glutamate as well as increasing serotonin release and inhibiting reuptake [40]. Fenfluramine showed $90 \%$ reduction of generalized tonic clonic seizures in this small open label study, while ataluren did not show efficacy $[41,42]$.

To date, no disease-modifying therapy exists for CDD but several are in development. A protein transduction domain (TAT)-CDKL5 fusion protein was efficiently internalized by target cells and retained CDKL5 activity, suggesting that CDKL5 protein therapy may be an effective clinical tool for the treatment of CDD [43]. A 
splicing correction strategy has been applied to CDKL5, developing engineered U1snRNA variants that were able to rescue CDKL5 mRNA splicing, protein synthesis, and function [44]. Other researchers induced escape of CDKL5 from $\mathrm{X}$ chromosome inactivation by editing DNA methylation on the promoter of CDKL5 using a dCas9-TET1 fusion protein [45]. Recently, the first proof-of-concept study on gene replacement as a potential approach for the treatment of CDD was published, using adeno-associated virus (AAV)-CDKL5 vectors in in vivo and in vitro models of CDD [46]. The authors cloned and produced AAV vectors expressing the major $C D K L 5$ brain isoforms and delivered them in a $C d k l 5$ $\mathrm{KO}$ mouse model as well as in a CDKL5-mutant iPSCderived neuron model [46]. Treatment in the mouse model led to improvements in motor functions and autistic-like behaviors compared to controls. In the neuron model, treatment led to an increased density of synaptic puncta and ameliorated the calcium signaling defect compared to controls [46]. Future proof-ofconcept studies are required to answer fundamental questions [47], but this study represents an important beginning for demonstrating the utility of virusmediated gene transfer in CDD [46].

\section{Limitations}

This study is limited by the mixed prospective and retrospective study design. Individuals were seen a variable number of times at the centers and did not necessarily receive their primary management at these centers. Treatment response was exclusively obtained retrospectively from medical records, making any conclusion about efficacy quite limited, so we mainly demonstrate treatment patterns. We are also not able to comment on order of use or specific combinations of medications from this dataset. Historical data for individuals enrolled in NHS were gathered primarily from a baseline visit, with additional data coming from $61 \%$ of individuals $(n$ $=25)$ seen for one follow-up, and 37\% $(n=15)$ seen for two follow-ups. Lastly, the majority of our cohort was white and non-Hispanic, likely due to disparities in testing or referrals. Future research would benefit from including a broader and more diverse sample.

\section{Conclusion}

Our study provides an overview of current treatment patterns for neurologic symptoms in CDD, including aspects of the disorder for which there is limited information in the literature such as treatment for sleep, behavior and movement disorders, as well as nonpharmacological treatments for epilepsy including ketogenic diet and surgery. By emphasizing the refractory nature of epilepsy in CDD and the lack of sustained effects of current treatments, we stress that new approaches are necessary to better care for this group of individuals. We provide a review of the latest emerging therapies for $\mathrm{CDD}$, including clinical trial medications and novel treatment approaches under development. Our data complement efforts toward defining treatment guidelines for CDD, with the hope of adding disease-modifying therapies to the treatment arsenal in the near future.

\section{Abbreviations}

CDD: CDKL5 deficiency disorder; ASM: Anti-seizure medication; KD: Ketogenic diet; VNS: Vagus nerve stimulator; BCH: Boston Children's Hospital;

CCF: Cleveland Clinic Foundation; CHCO: University of Colorado/Children's Hospital Colorado; NHS: Natural History Study; COE: Center of Excellence; IRB: Institutional Review Board; ILAE: International League Against Epilepsy

\section{Supplementary Information}

The online version contains supplementary material available at https://doi. org/10.1186/s11689-021-09384-z.

Additional file 1: Supplemental Table 1. Treatment response in 54 individuals with CDD treated with ketogenic diet. Supplemental Table 2. Response of 126 individuals with CDD to common sleep and behavioral medications

Acknowledgements

We would like to thank all of the individuals and families followed in our CDKL5 Centers of Excellence who participate in our research studies.

Authors' contributions

HEO conceptualized and designed the study. IH, CID, LCS, CAG, AMD, EPK, $X Z, A F, T A B, S D$, and $C F$ reviewed medical records and collected data. CID, $I H$, and $C F$ analyzed the data. $I H, C I D, H E O$, and LCS wrote the manuscript. $\mathrm{TAB}$ and $\mathrm{AP}$ provided insight into data collection and interpretation and edited the manuscript. All authors provided critical review and final approval of the manuscript.

\section{Funding}

Funding for the CDKL5 Centers of Excellence was provided by the International Foundation for CDKL5 Research. NIH funding includes the Rett and Rett-Related Disorders Natural History Study consortium (U54 HD061222) as well as Dr. Heather Olson's "Diagnosis and genotype-phenotype correlations in early life epilepsy and CDKL5 disorder" NINDS award

(1K23NS107646). Eunice Kennedy Shriver National Institute of Child Health and Human Development (U54 HD061222) additionally supported the Rett and Rett-Related Disorders Natural History Study. Dr. Benke was supported by the Rocky Mountain Rett Association.

\section{Availability of data and materials}

The datasets generated and/or analyzed during the current study are not publicly available due to identifiable information, but de-identified data from the CDKL5 Centers of Excellence are available from the corresponding author upon reasonable request. Data stored in the NHS database are governed by an $\mathrm{NIH}$ acceptable data sharing agreement and are now available via the database of Genotypes and Phenotypes (dbGaP).

\section{Declarations}

Ethics approval and consent to participate

This project was reviewed and approved by the Institutional Review Boards of Boston Children's Hospital, Cleveland Clinic Foundation, Colorado

Children's Hospital, and sites participating in the Rett and Rett-Related Disorders Natural History Study. Written informed consent to participate was obtained from parents or legal guardians of all participants. 


\section{Consent for publication}

Written informed consent for publication or waiver of consent to use retrospective data was obtained from parents or legal guardians for all individuals involved in the study.

\section{Competing interests}

Heather E. Olson: site PI of clinical trials in CDD sponsored by Ovid Therapeutics and Marinus Pharmaceuticals. PI of "Diagnosis and genotypephenotype correlations in early life epilepsy and CDKL5 disorder" NINDS award (1K23NS107646). Funding for the Boston Children's Hospital CDKL5 Center of Excellence provided by the International Foundation for CDKL5 Research. Consulting for Takeda and Ovid Therapeutics. Scott T. Demarest: site $\mathrm{PI}$ of clinical trials in CDD sponsored by Ovid Therapeutics and Marinus Pharmaceuticals. Consulting for Upsher-Smith and BioMarin. All remuneration has been made to his department. Elia Pestana-Knight: site PI of clinical trial in CDD sponsored by Marinus Pharmaceuticals. Co-PI of Cleveland Clinic CDD Center of Excellence established by the International Foundation for CDKL5 Research. Consultant for Marinus Pharmaceuticals. Ahsan N. Moosa: site coinvestigator for clinical trials in CDD sponsored by Marinus Pharmaceuticals. Bernhard Suter: site PI of a clinical trial in CDD sponsored by Marinus Pharmaceuticals. Site PI of a clinical trial in Rett syndrome sponsored by RSRT, the investigator-initiated trial using ketamine. PI of Texas Children's Hospital CDD Center of Excellence established by the International Foundation for CDKL5 Research. Jeffrey L. Neul: consultancy to GW Pharmaceuticals, Acadia, AveXis, Ovid Therapeutics. Data and Safety Monitoring Board for Roche, Ovid Therapeutics. Alan K. Percy: PI of the NICHD-funded Natural History Study. Site PI of clinical trials in Rett syndrome sponsored by Anavex and Acadia and the investigator-initiated trial using ketamine. Consultant with Acadia. Eric D. Marsh: site PI of clinical trial in CDD sponsored by Marinus Pharmaceuticals. Site PI for clinical trials for DS and LGS trials sponsored by Zogenix. Provides research support and clinical Center of Excellence support for the International Foundation for CDKL5 Research. Timothy A. Benke: site co-PI of clinical trials in CDD sponsored by Ovid Therapeutics and Marinus Pharmaceuticals. Consulting for AveXis, Ovid Therapeutics, Takeda, and Marinus Pharmeceuticals. All remuneration has been made to his department. Annapurna Poduri: SAB for TevardBio, no personal remuneration. Carolyn Daniels, Isabel Haviland, Lindsay Swanson, Caitlin Greene, AnneMarie M. Denny, Andrea Fidell, Cary Fu, Xiaoming Zhang, Judith L. Weisenberg: no competing interests.

\section{Author details}

'Division of Epilepsy and Clinical Neurophysiology, Department of Neurology, Boston Children's Hospital, 300 Longwood Avenue, Mailstop 3063, Boston, MA 02115, USA. ²Division of Pediatric Neurology, University of Saskatchewan, Saskatoon, SK, Canada. ${ }^{3}$ Children's Hospital Colorado, University of Colorado, School of Medicine, Aurora, CO, USA. ${ }^{4}$ Department of Pediatrics, School of Medicine, University of Colorado, Aurora, CO, USA. ${ }^{5}$ Epilepsy Center, Neurological Institute, Cleveland Clinic, Cleveland, OH, USA. ${ }^{6}$ Department of Pediatric Neurology, Washington University School of Medicine, St. Louis, MO, USA. `Division of Child Neurology, Texas Children's Hospital, Departments of Neurology and Pediatrics, Baylor College of Medicine, Houston, TX, USA. ${ }^{8}$ Department of Pediatrics, Vanderbilt University Medical Center, Nashville, TN, USA. ${ }^{9}$ Department of Pediatrics, University of Alabama at Birmingham, Birmingham, AL, USA. ${ }^{10}$ Division of Child Neurology, Children's Hospital of Philadelphia, Departments of Neurology and Pediatrics, Perelman School of Medicine, University of Pennsylvania, Philadelphia, PA, USA. ${ }^{11}$ Departments of Pharmacology, Neurology, and Otolaryngology, School of Medicine, University of Colorado, Aurora, CO, USA.

\section{Received: 12 February 2021 Accepted: 16 August 2021}

\section{Published online: 16 September 2021}

\section{References}

1. Demarest ST, Olson HE, Moss A, Pestana-Knight E, Zhang X, Parikh S, et al. CDKL5 deficiency disorder: Relationship between genotype, epilepsy, cortical visual impairment, and development. Epilepsia. 2019;60(8):1733-42. https://doi.org/10.1111/epi.16285.

2. Olson HE, Demarest ST, Pestana-Knight EM, Swanson LC, labal S, Lal D, et al. Cyclin-dependent kinase-like 5 deficiency disorder: clinical review. Pediatr Neurol. 2019;97:18-25. https://doi.org/10.1016/j.pediatrneurol.2019.02.015.
3. Fehr S, Wong K, Chin R, Williams S, de Klerk N, Forbes D, et al. Seizure variables and their relationship to genotype and functional abilities in the CDKL5 disorder. Neurology. 2016;87(21):2206-13. https://doi.org/10.1212/ WNL.0000000000003352.

4. Artuso R, Mencarelli MA, Polli R, Sartori S, Ariani F, Pollazzon M, et al. Earlyonset seizure variant of Rett syndrome: definition of the clinical diagnostic criteria. Brain Dev. 2009;32(1):17-24. https://doi.org/10.1016/j.braindev.2009. 02.004 .

5. Bahi-Buisson N, Nectoux J, Rosas-Vargas H, Milh M, Boddaert N, Girard B, et al. Key clinical features to identify girls with CDKL5 mutations. Brain. 2008; 131(Pt 10):2647-61. https://doi.org/10.1093/brain/awn197.

6. Fehr S, Wilson M, Downs J, Williams S, Murgia A, Sartori S, et al. The CDKL5 disorder is an independent clinical entity associated with early-onset encephalopathy. Eur J Hum Genet. 2013;21(3):266-73. https://doi.org/10.103 8/ejhg.2012.156.

7. Mangatt $\mathrm{M}$, Wong $\mathrm{K}$, Anderson B, Epstein A, Hodgetts $\mathrm{S}$, Leonard $\mathrm{H}$, et al. Prevalence and onset of comorbidities in the CDKL5 disorder differ from Rett syndrome. Orphanet J Rare Dis. 2016;11(1):39. https://doi.org/10.1186/ s13023-016-0418-y.

8. Cutri-French C, Armstrong D, Saby J, Gorman C, Lane J, Fu C, et al. Comparison of core features in four developmental encephalopathies in the Rett natural history study. Ann Neurol. 2020;88(2):396-406. https://doi.org/1 0.1002/ana.25797.

9. Fehr S, Leonard H, Ho G, Williams S, de Klerk N, Forbes D, et al. There is variability in the attainment of developmental milestones in the CDKL5 disorder. J Neurodev Disord. 2015;7(1):2.

10. Fehr S, Downs J, Ho G, de Klerk N, Forbes D, Christodoulou J, et al. Functional abilities in children and adults with the CDKL5 disorder. Am J Med Genet A. 2016;170(11):2860-9. https://doi.org/10.1002/ajmg.a.37851.

11. Müller A, Helbig I, Jansen C, Bast T, Guerrini R, Jähn J, et al. Retrospective evaluation of low long-term efficacy of antiepileptic drugs and ketogenic diet in 39 patients with CDKL5-related epilepsy. Eur J Paediatr Neurol. 2016; 20(1):147-51. https://doi.org/10.1016/j.ejpn.2015.09.001.

12. Lim Z, Wong K, Olson HE, Bergin AM, Downs J, Leonard H. Use of the ketogenic diet to manage refractory epilepsy in CDKL5 disorder: experience of >100 patients. Epilepsia. 2017:58(8):1415-22. https://doi.org/10.1111/ epi.13813.

13. Lim Z, Wong K, Downs J, Bebbington K, Demarest S, Leonard H. Vagus nerve stimulation for the treatment of refractory epilepsy in the CDKL5 deficiency disorder. Epilepsy Res. 2018;146:36-40. https://doi.org/10.1016/j. eplepsyres.2018.07.013.

14. Bahi-Buisson N, Kaminska A, Boddaert N, Rio M, Afenjar A, Gérard M, et al. The three stages of epilepsy in patients with CDKL5 mutations. Epilepsia. 2008;49(6):1027-37. https://doi.org/10.1111/j.1528-1167.2007.01520.x.

15. Olson H, Poduri A. CDKL5 mutations in early onset epilepsy: Case report and review of the literature. J Pediatr Epilep. 2012;1:151-9.

16. Takahashi Y, Sumit P, Pestana Knight EM. CDKL5 gene-related encephalopathy: pathophysiology, clinical presentation, developmental prognosis, and treatment. J Pediatr Epilepsy. 2018;7(1):001-7. https://doi. org/10.1055/s-0038-1641161.

17. Friedman SL, Moody E, Katz T. Sleep issues in patients with CDKL5 gene mutation. Toranto: Pediatric Academic Societies Annual Meeting; 2018.

18. Mori Y, Downs J, Wong K, Anderson B, Epstein A, Leonard H. Impacts of caring for a child with the CDKL5 disorder on parental wellbeing and family quality of life. Orphan J Rare Dis. 2017;12(1):16. https://doi.org/10.1186/s13 023-016-0563-3.

19. Weaving LS, Christodoulou J, Williamson SL, Friend KL, McKenzie OLD, Archer $\mathrm{H}$, et al. Mutations of CDKL 5 cause a severe neurodevelopmental disorder with infantile spasms and mental retardation. Am J Hum Genet. 2004;75(6):1079-93. https://doi.org/10.1086/426462.

20. Mei D, Marini C, Novara F, Bernardina BD, Granata T, Fontana E, et al. Xp22.3 genomic deletions involving the CDKL5 gene in girls with early onset epileptic encephalopathy. Epilepsia. 2010;51(4):647-54. https://doi.org/1 0.1111/j.1528-1167.2009.02308.x.

21. Liang JS, Shimojima K, Takayama R, Natsume J, Shichiji M, Hirasawa K, et al. CDKL5 alterations lead to early epileptic encephalopathy in both genders. Epilepsia. 2011;52(10):1835-42. https:/doi.org/10.1111/j.1528-1167.2011.03174.X.

22. Nemos C, Lambert L, Giuliano F, Doray B, Roubertie A, Goldenberg A, et al. Mutational spectrum of CDKL5 in early-onset encephalopathies: a study of a large collection of French patients and review of the literature. Clin Genet. 2009;76(4):357-71. https://doi.org/10.1111/j.1399-0004.2009.01194.x. 
23. Sartori S, Polli R, Bettella E, Rossato S, Andreoli W, Vecchi M, et al. Pathogenic role of the X-linked cyclin-dependent kinase-like 5 and aristaless-related homeobox genes in epileptic encephalopathy of unknown etiology with onset in the first year of life. J Child Neurol. 2011;26(6):683-91. https://doi.org/10.1177/0883073810387827.

24. Elia M, Falco M, Ferri $R$, Spalletta A, Bottitta M, Calabrese $G$, et al. CDKL5 mutations in boys with severe encephalopathy and early-onset intractable epilepsy. Neurology. 2008;71(13):997-9. https://doi.org/10.1212/01.wnl. 0000326592.37105.88.

25. Leonard H, Junaid M, Wong K, Demarest S, Downs J. Exploring quality of life in individuals with a severe developmental and epileptic encephalopathy, CDKL5 Deficiency Disorder. Epilepsy Res. 2020;169:106521.

26. Fisher RS, Cross JH, French JA, Higurashi N, Hirsch E, Jansen FE, et al. Operational classification of seizure types by the International League Against Epilepsy: Position Paper of the ILAE Commission for Classification and Terminology. Epilepsia. 2017;58(4):522-30. https://doi. org/10.1111/epi.13670

27. Olson H, Demarest S, Pestana-Knight E, Daniels C, Greene C, DeLeo M, et al. Infantile Spasms in CDKL5 Deficiency disorder respond poorly to first line treatments: American Neurological Association Annual Meeting; Virtual Event. Alexandria; 2020.

28. Aledo-Serrano Á, Gómez-Iglesias P, Toledano R, Garcia-Peñas JJ, GarciaMorales I, Anciones $C$, et al. Sodium channel blockers for the treatment of epilepsy in CDKL5 deficiency disorder: Findings from a multicenter cohort. Epilepsy Behav. 2021;118:107946.

29. Melikishvili G, Epitashvili N, Tabatadze N, Chikvinidze G, Dulac O, Bienvenu T, et al. New insights in phenomenology and treatment of epilepsy in CDKL5 encephalopathy. Epilepsy Behav. 2019;94:308-11. https://doi.org/10.1016/j. yebeh.2019.02.013.

30. Devinsky O, Verducci C, Thiele EA, Laux LC, Patel AD, Filloux F, et al. Openlabel use of highly purified CBD (Epidiolex ${ }^{\circledast}$ ) in patients with CDKL5 deficiency disorder and Aicardi, Dup15q, and Doose syndromes. Epilepsy Behav. 2018:86:131-7. https://doi.org/10.1016/j.yebeh.2018.05.013.

31. Freeman JM, Kossoff EH, Hartman AL. The Ketogenic diet: one decade later. Pediatrics. 2007;119(3):535-43. https://doi.org/10.1542/peds.2006-2447.

32. Mingorance A, Jaksha A, Smart T, Sherriff L, Valentine J. The voice of the patient report: CDKL5 deficiency disorder (CDD): Loulou Foundation; International Foundation for CDKL5 Research; 2019. https:/www.cdkl5.com/pfdd/

33. Nohria V, Giller E. Ganaxolone. Neurotherapeutics. 2007;4(1):102-5. https:// doi.org/10.1016/j.nurt.2006.11.003.

34. Carver CM, Reddy DS. Neurosteroid interactions with synaptic and extrasynaptic GABA(A) receptors: regulation of subunit plasticity, phasic and tonic inhibition, and neuronal network excitability. Psychopharmacology. 2013;230(2):151-88.

35. Pestana-Knight EM, Amin S, Benke TA, Cross JH, Olson HE, Specchio N, et al. Ganaxolone significantly reduces major motor seizures associated with CDKL5 deficiency disorder: A randomized, double-blind, pacebo-controlled phase 3 study (Marigold Study). Seattle: American Epilepsy Society Annual Meeting; 2020

36. Ganaxolone Achieves Primary Endpoint in Phase 3 Trial for CDKL5 Deficiency Disorder (CDD), a Rare Form of Genetic Epilepsy [press release]. Business Wire, September 14 2020. Available from: https://www. businesswire.com/news/home/20200914005828/en/

37. Ovid Therapeutics Provides Soticlestat (OV935/TAK-935) Results from ARCADE and ENDYMION studies showing seizure reduction in rare epilepsies [press release]. GlobeNewswire, September 30 2020. Available from: https://www.globenewswire.com/news-release/2020/09/30/2101306/ 0/en/Ovid-Therapeutics-Provides-Soticlestat-OV935-TAK-935-Results-from-A RCADE-and-ENDYMION-Studies-Showing-Seizure-Reduction-in-RareEpilepsies.html

38. Nishi T, Kondo S, Miyamoto M, Watanabe $S$, Hasegawa $S$, Kondo $S$, et al. Soticlestat, a novel cholesterol 24-hydroxylase inhibitor shows a therapeutic potential for neural hyperexcitation in mice. Sci Rep. 2020;10(1):17081. https://doi.org/10.1038/s41598-020-74036-6.

39. Fazzari M, Frasca A, Bifari F, Landsberger N. Aminoglycoside drugs induce efficient read-through of CDKL5 nonsense mutations, slightly restoring its kinase activity. RNA Biol. 2019;16(10):1414-23. https://doi.org/10.1080/154 76286.2019.1632633.

40. Kadam SD, Sullivan BJ, Goyal A, Blue ME, Smith-Hicks C. Rett syndrome and CDKL5 deficiency disorder: from bench to clinic. Int J Mol Sci. 2019:20(20): 5098. https://doi.org/10.3390/ijms20205098.
41. Devinsky O, King LT, Bluvstein J, Friedman D. Ataluren for drug-resistant epilepsy in nonsense variant-mediated Dravet syndrome and CDKL5 deficiency disorder. Ann Clin Transl Neurol. 2021;8(3):639-44. https://doi. org/10.1002/acn3.51306.

42. Devinsky O, King LT, Schwartz D, Conway E, Price D. Effect of fenfluramine on convulsive seizures in CDKL5 deficiency disorder. Epilepsia. 2021;62(7): e98-e102. https://doi.org/10.1111/epi.16923.

43. Trazzi S, De Franceschi M, Fuchs C, Bastianini S, Viggiano R, Lupori L, et al. CDKL5 protein substitution therapy rescues neurological phenotypes of a mouse model of CDKL5 disorder. Hum Mol Genet. 2018;27(9):1572-92. https://doi.org/10.1093/hmg/ddy064.

44. Balestra D, Giorgio D, Bizzotto M, Fazzari M, Ben Zeev B, Pinotti M, et al. Splicing mutations impairing CDKL5 expression and activity can be efficiently rescued by U1snRNA-based therapy. Int J Mol Sci. 2019;20(17): 4130. https://doi.org/10.3390/ijms20174130.

45. Halmai JANM, Deng P, Gonzalez CE, Coggins NB, Cameron D, Carter JL, et al. Artificial escape from XCl by DNA methylation editing of the CDKL5 gene. Nucleic Acids Res. 2020;48(5):2372-87. https://doi.org/10.1093/nar/ gkz1214.

46. Gao Y, Irvine EE, Eleftheriadou I, Naranjo CJ, Hearn-Yeates F, Bosch L, et al. Gene replacement ameliorates deficits in mouse and human models of cyclin-dependent kinase-like 5 disorder. Brain. 2020;143(3):811-32. https:// doi.org/10.1093/brain/awaa028.

47. Benke TA, Kind PC. Proof-of-concept for a gene replacement approach to CDKL5 deficiency disorder. Brain. 2020;143(3):716-8. https://doi.org/10.1093/ brain/awaa055.

\section{Publisher's Note}

Springer Nature remains neutral with regard to jurisdictional claims in published maps and institutional affiliations.

Ready to submit your research? Choose BMC and benefit from:

- fast, convenient online submission

- thorough peer review by experienced researchers in your field

- rapid publication on acceptance

- support for research data, including large and complex data types

- gold Open Access which fosters wider collaboration and increased citations

- maximum visibility for your research: over $100 \mathrm{M}$ website views per year

At BMC, research is always in progress.

Learn more biomedcentral.com/submissions 